\title{
Research on rescuers' training process in toxic I explosive / flammable environments
}

\author{
Andrei-Lucian Gireadă*, Cosmin Ilie, and Alin Irimia \\ National Institute for Research and Development in Mine Safety and Protection to Explosion - \\ INSEMEX Petroşani, Romania
}

\begin{abstract}
The paper presents the structuring of physical effort put in by rescuers during training, taking into account the activity specific psychosocial factors, structuring that aimed at streamlining the training process of intervention and rescue personnel in toxic / explosive / flammable environments. Training routes with various degrees of difficulty, allowing the simulation of intervention activities in horizontally and vertically confined spaces, low visibility, high temperature and humidity environments were analysed, for each the specific labour consumption being calculated. A dysfunctional phenomenon caused by the intervention and rescue activity is fatigue, perceived as a body reaction to readjust and restore its functions following intense or repeated body requests for energy consumption. Not only physical fatigue (which can be controlled through exercises) is specific for rescue and intervention activity but also mental fatigue. In addition to physical and technical training, psychosocial training of people who carry out intervention and rescue activities was followed in the training programs.
\end{abstract}

\section{Introduction}

The activity in special conditions created as a result of underground or surface damage, that endangers personnel or material goods and which, because of concentrations of toxic or asphyxiating gases, vapours or dusts exceeding limits established by norms, requires the use of respirators $[1,2]$. The direct performer of heavy and dangerous activities for rescuing people and protecting industrial objective is the operative intervention and rescue personnel, who use respiratory protection devices based on compressed air and respectively, compressed oxygen [2].

In recent decades, as a consequence of accelerated economic development, occupational and industrial risk issues, as well as the level of real risk diversification, have become increasingly important. [4].

From the research carried out, it can be concluded that the training of rescuers in the training ground will lead to an increase in the level of safety and health at work, by increasing the capacity to intervene in high safety conditions. [6].

\footnotetext{
${ }^{*}$ Corresponding author: andrei.gireada@insemex.ro
} 


\section{The training process}

Training is a process of psychophysiological preparation through which an increased (maximum) efficiency is obtained in the professional activity of rescuers [2, 3]. The maximum efficiency is obtained by raising the body's functional capacity to highest degree [3]. For this it is necessary to use systematic and methodical exercise according to pedagogical rules.
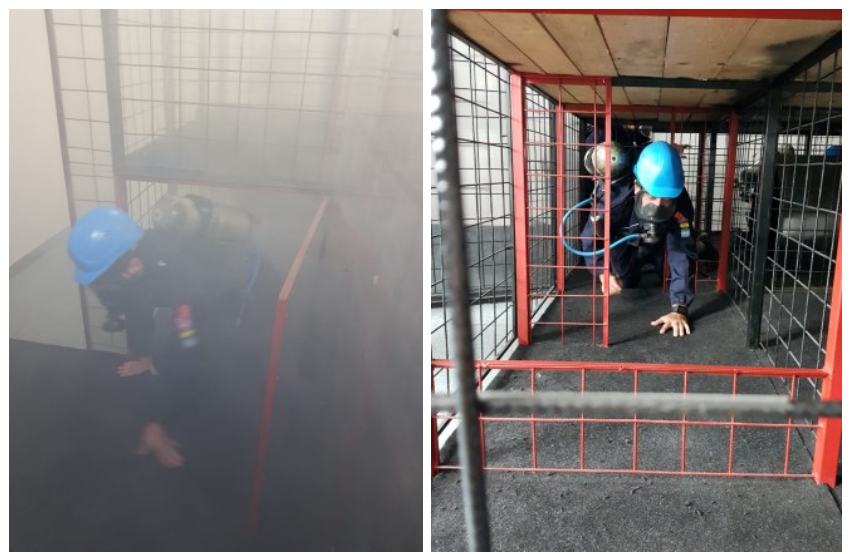

Fig. 1. Training process

The intensity of performing exercises during training is conditioned by:

- individual possibilities of rescuers;

- degree of training;

- nature of exercises;

- external deployment conditions.

Their succession and gradation are rigorously planned, ensuring that training has a scientific character [4]. During training the following psychophysiological objectives are pursued: learning motor skills, developing mental and physical qualities of motor activity: speed, endurance, skill, will, self-confidence, courage, determination, initiative [5].
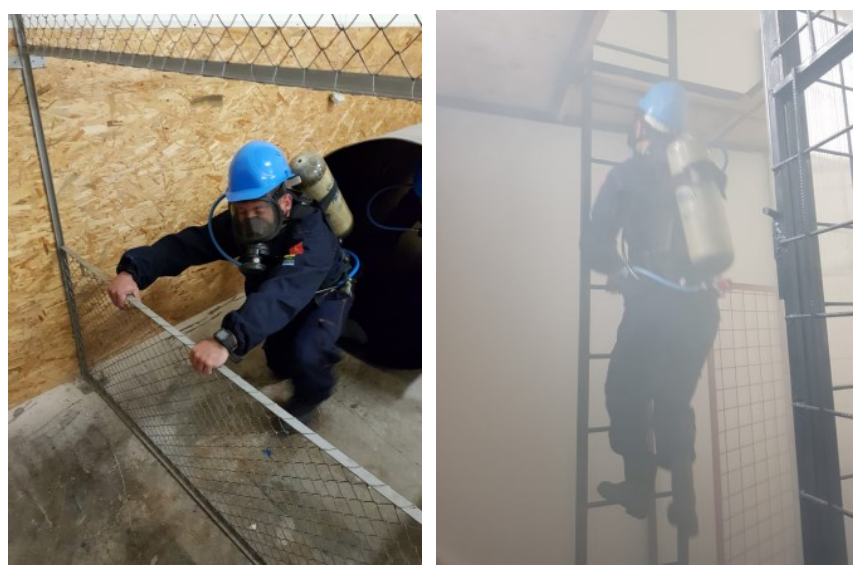

Fig. 2. Training process 
Learning and developing motor skills is done with participation of the central nervous system, which ensures the body's functions efficiency increase and through it, a high level of activity of the musculoskeletal system $[5,6]$.

\section{Calculation of labour consumption in rescuers' training exercises}

When working with a respirator, there are a number of factors that contribute to work becoming stressful. Usually, those who work under the protection of respiratory protection devices, in addition to the fact that they carry a device that weighs $14-18 \mathrm{~kg}$, are also subjected to actions of great difficulty, as ensuring their own safety, saving lives, performing fast, urgent and highly qualified activities (insulation of damaged areas, work in flooded areas, transport of materials or injured people through works with reduced profiles, etc.) in severe microclimate (high heat and humidity), toxic environment, smoke etc [6]. Thus, the physical effort put in by rescuers is intense, because of the conditions mentioned above. Normal activity is defined as work performed by a worker with average performance capacity, trained, accustomed to his work, working at a moderate pace, taking rest periods according to his needs. During effort, the body's adaptation is ensured on one hand by nervous regulation and on the other hand by neuro-hormonal regulation [7].

During exercise, there are a number of changes in the body's apparatus and systems, as an expression of the tendency of functional adaptation, changes that are most pronounced in the activity of the cardiovascular system [10]. The most obvious adaptation of the cardiovascular system is heart rate acceleration, increased frequency of heartbeats, reflecting the increase of its rhythm. From 60-70 beats per minute, heart rate can reach $120-160$ or even 200 beats per minute in exceptional cases, at very high efforts. Adjustment of the heart rate begins immediately after effort begins, first with an increase over the necessary and then a stabilization at a level that remains constant, if effort is constant $[8,9]$.

After the effort ends, return to normal is done in two stages: first by a sudden decrease, at the beginning, then by a slow and progressive, sometimes wave-like, decrease. Another manifestation of circulatory changes during exertion is increased blood pressure, which is proportional to the intensity of exertion, in this situation both maximum and minimum being of interest [9]. After the training ends, tension returns to normal, a return that depends on the intensity of effort that was put in and on the personal fitness of individuals performing the training. In the first minutes, blood pressure values fall below the rest figure, then rise to normal values. In case of an inadequate adaptation of the cardiovascular system, maximum blood pressure drops suddenly before the exercise ends, so the heart is at the limit of its resources. After the effort ends, muscle masses that were in full activity still need a certain period of time to eliminate the substances of wear, a period that is a function of the mechanical work performed [10]. Repeated physical activity causes the circulatory system to adapt to increased demands, the heart increases in volume, the circulatory force increases, and its frequency decreases. As you train, your blood pressure settles to lower and lower values [9].

The phenomenon of fatigue during training represents the totality of subjective and objective phenomena that occur as a result of physical exertion and involves accompanying sensations of effort as well as consecutive repair phenomena. It is characterized by more or less prolonged temporary decrease of work capacity, determined by duration and intensity of effort, being a signal that sets in motion a complex of functional processes. Fatigue occurrence shows great differences from individual to individual. In case of fatigue there is a favourable situation, given by training and lifestyle, so it has the possibility of being positively influenced [10]. 
In order to determine how pulse, blood pressure and critical frequency of fusion evolve in rescuers equipped with respiratory protection devices who put in great efforts (approx. $20,000 \mathrm{kgm}$, a performance considered to be very high and which requires an intense effort), practical training exercises were performed on the ergometer and the ergometer bicycle. The effort is intense in these cases and maximum pulse changes must frame between 150-175 pulses per minute [10].

From keeping track of physiological changes to effort it was established that:

- pulse and blood pressure changes are easily accessible to medical observation, being illustrative for assessing the degree of body stress;

- when putting in effort whilst wearing insulating apparatuses, it is estimated that the body is subjected to a $30 \%$ extra load, a figure that is taken into account as reference when appraising rescuer's effort [9].

To cope with such overload, proper training of rescuers is required as well as periodic test for establishing the degree and ability at effort, constantly monitoring physiological parameters by means equipment of the mobile training facility or by rescue station's doctor [12]. The effort that rescuers put in in the training room, is expressed in $\mathrm{Kgm}$ and, depending on the facilities they work on, is calculated with equations in which the following notations are used:

$\mathrm{p}$ - weight of transported objects, $(\mathrm{Kg})$;

$\mathrm{P}$ - weight of the rescuer together with the respiratory protection device, $(\mathrm{Kg})$;

1 - length of the track $(\mathrm{m})$;

$\mathrm{z}$ - number of repeated passes;

$\mathrm{t}$ - duration of the activity, (min.), without including the rest period;

$\mathrm{S}$ - length of the crossing road, (m);

$\mathrm{h}$ - weight lifting height, (m);

$\mathrm{n}$ - number of lifts;

$\mathrm{a}-$ track's angle of inclination.

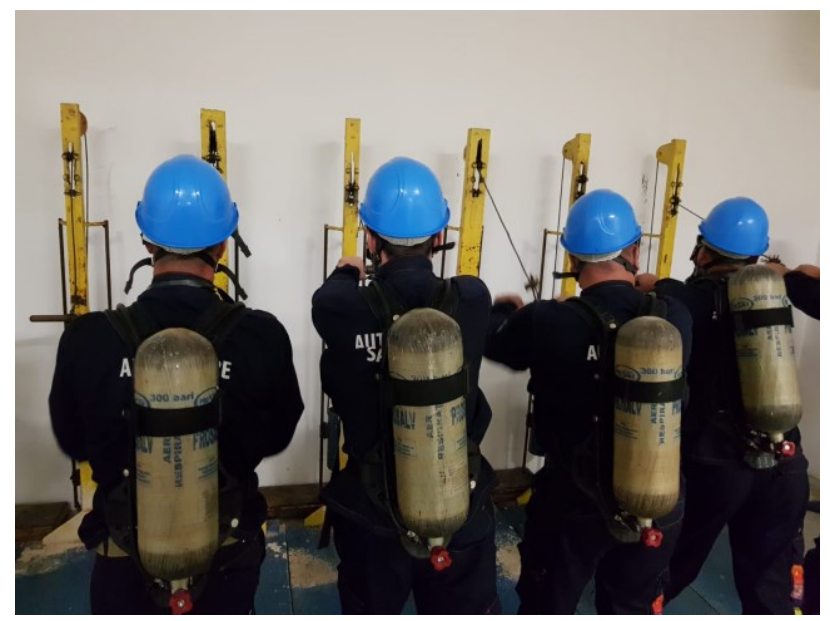

Fig. 3. Work consumption

Numerical values $(120,140,500,0.005,0.125,0.25,0.5,580)$ experimentally established, based on energy consumption measurements, are also used in these calculations.

The amount of work performed in the training room must be equivalent to:

- 15,000 Kgm for rescuers under training;

- 20,000 Kgm for rescuers having over 2 years of activity.

The general calculation of labour consumption in rescuers' training exercises is: 
- The amount of work put in for passing through a portion of low-profile gallery, having a section of $0.54 \mathrm{~m}^{2}$, by dragging, is established with the relation:

$$
A_{1}=0,5 \cdot P \cdot S(\mathrm{Kgm})
$$

- The amount of work put in for passing through a portion of low-profile gallery, having a section of $0.9 \mathrm{~m}^{2}$, on all fours, is established with the relation:

$$
A_{2}=0,2 \cdot P \cdot S(\mathrm{Kgm})
$$

- The amount of work put in for passing through a portion of low-profile gallery, having a section of $1.5 \mathrm{~m}^{2}$, in bent walking position, is established with the relation

$$
A_{3}=0,1 \cdot P \cdot S(\mathrm{Kgm})
$$

- The amount of work put in for getting through a mining work with a normal (horizontal) profile is established with the relation:

$$
A_{4}=0,055 \cdot P \cdot S(\mathrm{Kgm})
$$

- The amount of work put in to lift a weight on the ergometer is determined by the relation:

$$
A_{5}=p \cdot h \cdot n(K g m)
$$

- The amount of work put in for climbing a vertically placed ladder, in a rhythm of one movement per second, is established with the relation:

$$
A_{6}=580 \cdot t(\mathrm{Kgm})
$$

- The amount of work put in for building an insulation construction, using arch bricks to support the work, is established with the relation:

$$
A_{7}=120 \cdot t(\mathrm{Kgm})
$$

- The amount of work put in for building an insulation construction, using wood trunks to support the work, is established with the relation:

$$
A_{8}=140 \cdot t(\mathrm{Kgm})
$$

- The amount of work put in for getting through a mining work with a normal (horizontal) profile, on a ergometer, is established with the relation:

$$
A_{9}=0,055 \cdot P \cdot S(\mathrm{Kgm}) \quad(9)
$$

- The amount of work put in for getting through a mining work, by going up and down the 5-step ladder, is established with the relation:

$$
A_{10}=0,25 \cdot P \cdot S(\mathrm{Kgm})
$$

- The total amount of work put in is determined by the relationship:

$$
A=\Sigma A_{l} \div A_{n} \quad(\mathrm{Kgm})
$$

Three types of training routes with various degrees of difficulty were analysed and configured, for each training group - under training rescuers and rescuers having more than 2 years of activity - that allow the simulation of intervention activities in horizontally and vertically confined spaces, low visibility, high temperature and humidity environment, etc., the specific labour consumption being calculated for each of them. An optimal route will be chosen, depending on each rescuers' fitness status [10].

\subsection{Under training rescuers}

\section{Route no. 1 - surface}

Within the training facility, a team of surface rescuers, taking part at their first training, performed several types of exercises with various degrees of difficulty:

- two circuits of the confined space route;

- three series of 80 tractions per ergometer;

- five minutes of walking on the ergometric conveyor belt;

- ascending and descending the metal ladder 50 times;

- going up and down the well ladder;

- two turns of the modular circuit. 
The total amount of work put in by an under-training surface rescuer, to cover the first training route was $20,000 \mathrm{Kgm}$.

Fig. 4. Rescuers' training

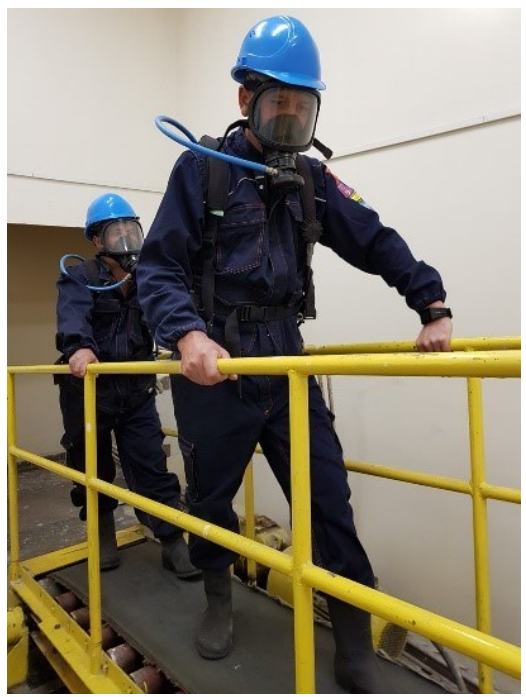

\section{Route no. 2 - surface}

Within the training facility, a team of 3 surface rescuers, taking part at their first training, performed several types of exercises with various degrees of difficulty:

- two circuits of the confined space route;

- two series of 55 tractions per ergometer;

- five minutes of walking on the ergometric conveyor belt;

- ascending and descending the metal ladder 30 times;

- going up and down the well ladder;

- two turns of the modular circuit.

The total amount of work put in by an under-training surface rescuer, to cover the first training route was $20,100 \mathrm{Kgm}$.

\section{Route no. 3 - surface}

Within the training facility, a team of 3 surface rescuers, taking part at their first training, performed several types of exercises with various degrees of difficulty:

- one circuit of the confined space route;

- two series of 40 tractions per ergometer;

- five minutes of walking on the ergometric conveyor belt;

- ascending and descending the metal ladder 20 times;

- going up and down the well ladder;

- one turn of the modular circuit.

The total amount of work put in by an under-training surface rescuer, to cover the first training route was $20,250 \mathrm{Kgm}$.

\subsection{Rescuers having more than $\mathbf{2}$ years of activity}

\section{Route no. 1 - surface}

Within the training facility, a team of 3 surface rescuers, taking part at their retraining, performed several types of exercises with various degrees of difficulty: 
- two circuits of the confined space route;

- four series of 80 tractions per ergometer;

- ten minutes of walking on the ergometric conveyor belt;

- ascending and descending the metal ladder 100 times;

- going up and down the well ladder;

- two turns of the modular circuit.

The total amount of work put in by an under-training surface rescuer, to cover the first training route was $15,200 \mathrm{Kgm}$.

Fig. 5. Rescuer training

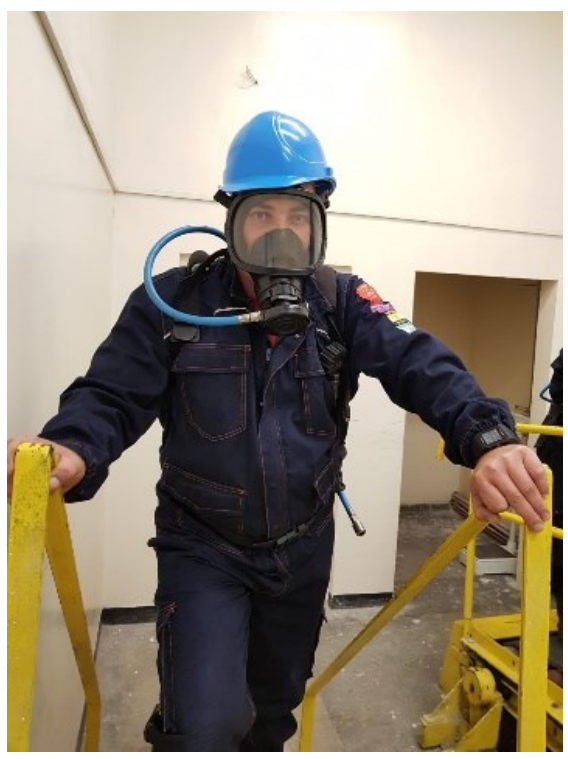

\section{Route no. 2 - surface}

Within the training facility, a team of 3 surface rescuers, taking part at their retraining, performed several types of exercises with various degrees of difficulty:

- three circuits of the confined space route;

- three series of 60 tractions per ergometer;

- five minutes of walking on the ergometric conveyor belt;

- ascending and descending the metal ladder 80 times;

- going up and down the well ladder;

- two turns of the modular circuit.

The total amount of work put in by an under-training surface rescuer, to cover the first training route was $15,100 \mathrm{Kgm}$.

\section{Route no. 3 - surface}

Within the training facility, a team of 3 surface rescuers, taking part at their retraining, performed several types of exercises with various degrees of difficulty:

- two circuits of the confined space route;

- two series of 40 tractions per ergometer;

- five minutes of walking on the ergometric conveyor belt;

- ascending and descending the metal ladder 60 times;

- going up and down the well ladder;

- one turn of the modular circuit. 
The total amount of work put in by an under-training surface rescuer, to cover the first training route was $15,000 \mathrm{Kgm}$.

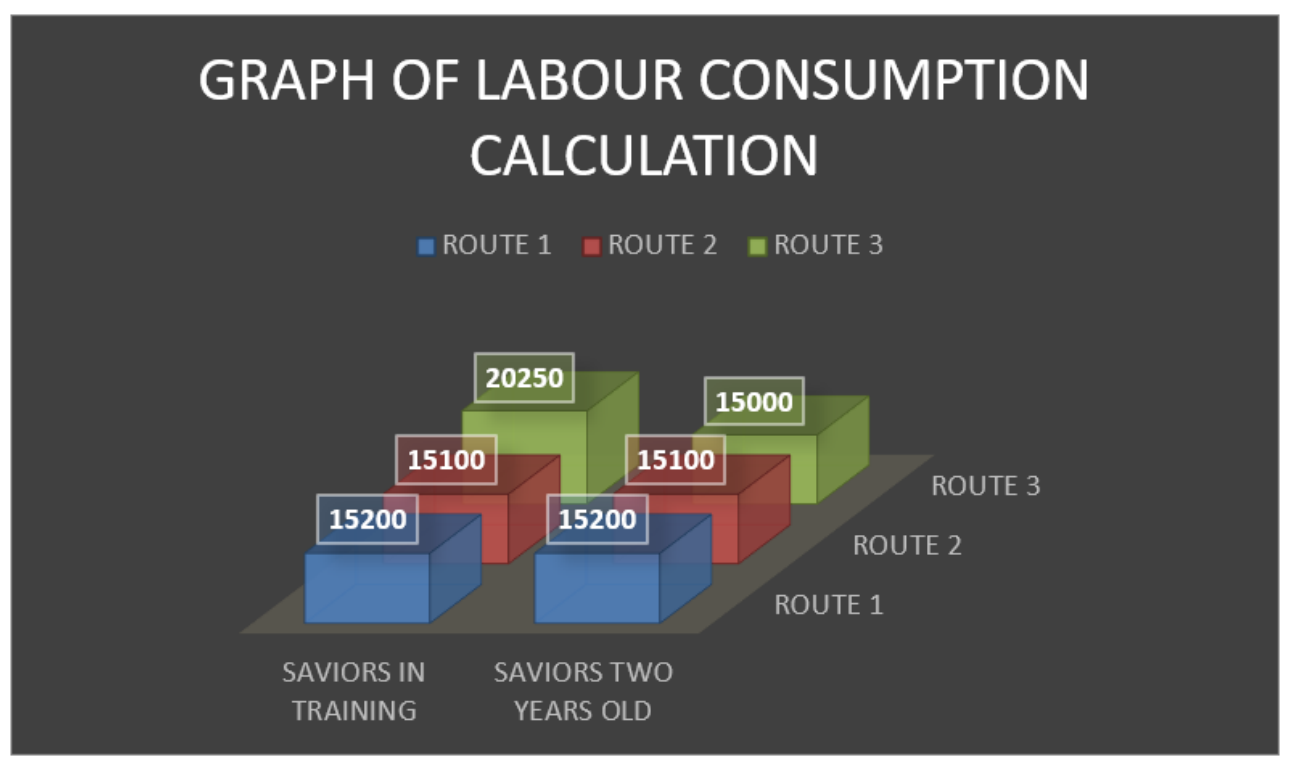

Fig. 6. Graph of labour consumption calculation

\section{Conclusions}

Training of rescuers in the training facility in confined and narrow spaces, leads to increased levels of safety and health at work, by increasing the capacity to intervene in high safety conditions, in case of damage, accidents, disasters, etc.

Rescue activities in toxic / explosive / flammable environments, whether in response to incidents, simulated emergencies or training activities, face dangerous situations.

When properly recognized and managed, hazards can be reduced to an acceptable level of risk. Obviously, acceptability of a risk depends on how important the outcome of the operation involving that risk is. If people's lives are in danger, more dangerous operations are allowed, ensuring that risks are recognized and measured. It is a practical use of hazard identification and control.

Despite all technical and technological advances, most industries suffer damage resulting in human casualties and material damage. For this reason, the presence of special intervention / rescue teams to limit / eliminate damage that generates toxic/explosive/flammable environments and rescue personnel caught by such events, at industrial units, is essential.

The intervention activity in such special conditions can be carried out exclusively by trained and authorized personnel in this respect, personnel using individual respiratory protection equipment.

The decisive factor in ensuring the success of an intervention-rescue operation in dangerous environments lies in the use of reliable personal protective equipment, in perfect working condition, whose characteristics are identical to those predetermined.

\section{References}

1. D. Pupazan, C. Ilie, A. Irimia, A. Gireada, I. Kovacs - Study on the behaviour of mine rescue brigadesmen exposed to high temperature and humidity in the training facility, 
Environmental Engineering and Management Journal June 2017 Vol.16 No. 6 ISSN 1582 9596.

2. I. Kovacs, D. Pupazan, C. Nicolescu, A. Irimia, A. Gireada, C. Ilie, Research on psychological indicators involved in rescue activities, 8th International Multidisciplinary Scientific Symposium „UNIVERSITARIA SIMPRO” Conference Proceedings ISSN-L 1842 - 4449 ISSN $2344-4754$.

3. A. Gireada, G.A. Gaman, C. Nicolescu, C. Ilie, A. Irimia, I. Kovacs, Research on establishing the physical effort of rescuers according to the activity performed and type of respiration protection equipment, 8th International Multidisciplinary Scientific Symposium „UNIVERSITARIA SIMPRO” Conference Proceedings ISSN-L 1842 - 4449 ISSN 2344 4754.

4. I. Kovacs, G.A. Gaman, D. Pupazan, C. Ilie, A. Gireada, Psychological training program for intervention and rescue personnel, Environmental Engineering and Management Journal April 2019, Vol.18 No. 4 ISSN 1582 - 9596.

5. I. Kovacs, G.A. Gaman, C. Ilie, A. Irimia, A. Gireada, Study on cognitive behavioural coping of intervention and rescue personnel in toxic / flammable / explosive environments, MATEC Web of Conferences Volume 121 (2017) 8th International Conference on Manufacturing Science and Education - MSE 2017 "Trends in New Industrial Revolution" Sibiu, Romania, June 7-9, 2017 eISSN: 2261-236X.

6. A. Gireada, G. A. Gaman, C. Ilie, D. Pupazan, C. Nicolescu, Research on changes of rescuer's energy consumption depending on their activity and type of respiratory protection equipment, 18th International Multidisciplinary Scientific GeoConference - SGEM 2018 Confernce Proceedings Vol. 18, ISSUE 1.3, ISBN 978-619-7408-37-9 ISSN 1314-2704.

7. C. Ilie, G. A. Gaman, D. Pupazan, C. Nicolescu, A. Gireada, Research on development of practical abilities of rescuers in interventions in high temperature and humidity environments, 19th International Multidisciplinary Scientific Geoconference SGEM 2019 Conference Proceedings Vol. 19 Science and Technologies in Geology, Exploration and Mining ISSUE 1.3, pag.537-544 ISBN 978-619-7408-78-2.

8. G. A. Gaman, D. Pupazan, C. Ilie, A. Calamar, A. Irimia, A. Gireada, R. Berca, Occupational Health and Safety, SESAM 2015.

9. C. Ilie, G. A. Gaman, D. Pupazan, A. Calamar, A. Gireada, Raising economic agent's resilience in case of damages in toxic/explosive/flammable environments by implementing intervention and rescue activities in hazardous environments, 11 th International Conference "Environmental Legislation, Safety Engineering and Disaster Management" 26 - 28 May 2016, Cluj-Napoca.

10. A. Gireada, D. Pupazan, C. Nicolescu, C. Ilie, A. Irimia, Optimizing the training process of intervention and rescue personnel in toxic / explosive / flammable environments, INSEMEX Publishing House, Petrosani 2019 